\title{
Exposure to particles and respiratory symptoms in stone carvers of Kerman, Iran
}

\author{
Ashrafi Asgarabad A, MSc${ }^{1}$, Samareh Fekri M, $\mathrm{PhD}^{2}$, Khanjani N, $\mathrm{PhD}^{3}$, Ghotbi Ravandi MR, $\mathrm{PhD}^{* 4}$ \\ 1- Faculty Member, Faculty of Public Health, Bam Medical University, Bam, Iran. 2- Assistant Prof., Pulmonologist, Dept \\ of Internal Medicine, Faculty of Medicine, Kerman Medical University, Kerman, Iran. 3- Assistant Prof., Research Center \\ for Environmental Health Engineering, Faculty of Public Health, Kerman Medical University, Kerman, Iran. 4- Assistant \\ Prof., Dept of Occupational Health, Faculty of Public Health, Kerman Medical University, Kerman, Iran.
}

\begin{abstract}
Received: April 2014, Accepted: November 2014

Background: Exposure to respirable particulate matter containing silica in the working environment can lead to respiratory diseases and other health hazards. The current study was designed to estimate the prevalence of lung diseases and their determining factors in the stone carvers of Kerman, Iran.

Materials and Methods: This was a cross-sectional study in which 67 male workers exposed to stone carving dust and 67 unexposed workers who were matched in regard to different characteristics were evaluated. Questionnaires were completed by the participants and chest radiography and spirometry were perfomed for each participant. Different outcomes were compared between the exposed and unexposed groups and also subgroups of the exposed. Data were analyzed using chi-square, t-test, Pearson's correlation, and logistic regression through SPSS 16 and STATA 12 software.

Results: The mean annual cumulative exposure to respirable dust was $3.8 \mathrm{mg} / \mathrm{m}^{3}$, which was higher than the permissible limit. Symptoms, such as frequent coughs, wheezing, dyspnea, rhinorrhea, sinusitis, and hyposmia, were more prevalent in the exposed workers. Some pulmonary function parameters had decreased significantly in the exposed workers. Some factors related to working conditions, such as working in confined environments, small workshops, not using appropriate masks, increased daily working hours, and increase in working days, were significantly associated with exacerbation of respiratory symptoms.

Conclusions: Despite the strong presence of the healthy worker effect, our study shows that high occupational exposure to particulate dust has led to respiratory symptoms, radiographic abnormalities, and decreased lung function in stone carvers of Kerman. This study urges more surveillance and control over works exposed to dust in developing countries.
\end{abstract}

Keywords: Pulmonary, Dysfunction, Signs and Symptoms, Respiratory, Iran

\section{Introduction}

Silica exists in different forms, such as quartz (1). According to the National Institute of Safety and Health (NIOSH), industries in which workers are exposed to crystaline silica consist of stone carving, granite carving, mining, asphalt working, filing, tiling, and cement factories (2). Stone carving is an occupation in which big stones are cut, broken, and polished and shaped into different designs and sizes and different objects, such as decours, statues, or grave stones, are made. This process can be undertaken by hand or by machine. In this occupation, chronic exposure to dust and silica coarse particles under $10 \mu \mathrm{m}$ in the working enviroment can lead to pulmonary inflammation, fibrosis, dysfunction, and a fatal condition called silicosis (3).

Silicosis is a pulmonary debilitating disease with a world wide scope, which leads to premature death due to secondary pulmonary tuberculosis, obstructive pulmonary diseases, and fatal lung and heart failure (4). This disease has 3 different clinical features; acute, accelerated, and chronic. Chronic silicosis

* Corresponding author: Mohammadreza
Ghotbiravandi, Dept of Occupational Health, Faculty of
Public Health, Kerman University of Medical Science,
Kerman, Iran.
Email: ghotbi@kmu.ac.ir


occurs after at least 10 years, accelerated silicosis between 5 to 10 years, and acute silicosis can occur from between a few weeks to 5 years after exposure. The exposure concentration is a determining factor in causing silicosis. As the disease progresses, signs, such as dyspnea, severe coughs, fatique, loss of appetite, chest pain, and fever, may appear (5-7). Inhalation of silica can lead to fibrosis in the gas exchanging units of the lungs and low oxygen concentrations (8). The particles decrease respiratory volumes by creating fibrotic tissue and inflammation (9). Decrease in lung capacity can lead to a series of pulmonary and non-pulmonary complaints, such as obstructive pulmonary diseases including chronic bronchitis, emphysema, rheumatoid artritis, cancer, and tuberculosis in the workers exposed to silica (10). Smoking and addiction in combination with exposure to silica particles have a synergistic effect and can exacerbate respiratory disease and facilitate the progress toward lung cancer (1014).

NIOSH has estmated that about 1.7 milion workers in America are exposed to crystal silica annually (15). In Quebec, between 1988 and 1994, about 40 new cases of silicosis were diagnosed among workers, 12 of which were under 40 years of age (16). In Brazil, in 2002, the prevalence of silicosis among 42 stonecarvers under study was about $53.7 \%$ and the dust concentration in $91 \%$ of the workshops was higher than the permissible amount (17). In an outbreak of silicosis in Spanish quartz conglomerate workers in 2014, 91.3\% were diagnosed with simple chronic silicosis using high-resolution computerized tomography (HRCT) scan (18).

Until now, few studies have been undertaken on the health status of stonecarvers in Iran. No studies exist about the stonecarvers in Kerman, Iran. Therefore, in this study, we aimed to estimate the amount of exposure to particles and study the prevalence of various respiratory symptoms among the stone carvers and stone cutters of Kerman.

\section{Materials and Methods}

This was a cross-sectional study conducted in 2012. We intended to enrol all workers of the stone carving workshops of Kerman in this study. The only exclusion criteria was not consenting to participate.

In order to enrol all stone carvers, a meeting was organised at the stone carvers' and stone cutters' organization. There were 35 stone cutting or stone carving workshops in Kerman. All of the stone carvers and stone cutters in Kerman $(n=75)$ were invited for this meeting through the stone carvers association. In total, 25 individuals participated in the meeting and signed the participation form. These people were informed of the project and asked to notify all of their colleagues about the research and invite them to participate in the study. Finally, 67 stone carvers particpated in the study, attended medical examinations, and completed the questionnaires.

In this gathering, the project, its aims, and the tasks that were going to be performed were explained. Signed permissions were acquired in order to visit the workshops and complete the questionnaires. The address and telephone number of all stone carvers were inquired. Later, the researchers visited the workshops, and after obtaining the workers' consent, 2 separate questionnaires, one about dust exposure and the other about their symptoms, were completed for each worker. Moreover, 2 coupons were given to each of them; one for doing a chest $\mathrm{X}$-ray and the other for visiting a respiratory physician (for a physical exam and a spirometry).

The face and content validity of the exposure questionnaire was confirmed before starting the study and its reliability was tested using test-retest and Cronbach's alpha in a pilot study. The test-retest correlation was 0.96 and the Cronbach's alpha was 0.86 . The exposure questionnaire included questions related to demographic characteristics (10 questions), history of silica exposure (19 questions), workshop chracteristics (4 questions), and the 
workers' smoking or addiction status (23 questions).

Clinical signs were evaluated using a checklist and all physical exams were conducted by a respiratory physician and included 20 items. The symptoms questionnaire was a standard questionnare used in the study of coal workers' pneumoconiosis (19). The questionnaire was obtained from the NIOSH website and included 60 questions about coughing, sputum, dyspnea, wheezing, rhinorrhea, and respiratory diseases.

All workers were referred to a radiologist to take a chest X-ray, the roentgenographic interpretation form from the Coal Worker's Health Surveillance Program of NIOSH was completed by a radiologist. In this form, the radiologist is prompted to report any parenchymal or pleural abnormalities consistent with pneumoconiosis, any small or large opacities, pleural plaues, costophrenic angle obliteration, pleural thickening, or any other abnormalties (20).

Spirometry was performed by a respiratory specialist and according to the standards of the American Thoracic Society. In order to determine pulmonary capacities, the Microlab device was used. Each parameter of the lung function was determined according to the persons age, height, sex, and race. The workers were asked to refrain from smoking and bathing at least 2 hours before the spirometry. In addition, they were provided with the necessary education for performing the spirometry. Before the test was performed, the workers were asked to sit for at least 5 minutes. Then, they were asked to stand in front of the device comfortably and casually and put the special peg on their nose. This maneuver was implemented at least 3 times. If there was a significant difference between the results of the forced vital capacity (FVC) of a worker, the test would be repeated at least 8 times. Subsequently, the greatest volumes were chosen as the results. The predicted percentages of pulmonary function were the volumes measured by the spirometer divided by the predicted capacity (according to sex, age, weight, height, and race) times 100 . The stone carvers working devices were classified into 3 groups (high, medium, and low dust producing devices) according to the comments of the worker themselves, the researchers' observation of the stone carvers while working and the amount of observed dust produced while working with the device.

The frequency of using these devices along with other working characteristics of the population under study (such as working inside or outside of the workshop, using appropriate masks, and suitable ventilation) have been summarized in table 1 . Suitable ventilation was based on the researchers' observation and whether the workshop ventilator was able to clear the respiratory space surrounding the worker or not and the worker was actually breathing in the dust cloud surrounding his head during work.

The comparison population in this study was selected from workers of a sign making factory. More than 100 workers worked in the sign making factory. The duty of these workers was to assemble parts of signs and they were not exposed to dust. After acquiring the necessary permits, 67 matching workers were chosen from this factory. These workers were all male and were matched based on age \pm 2 and working years \pm 2 with the stone carvers. We also tried to match the workers based on smoking, addiction, and marital status. However, in a few cases matching was not possible.

The mean estimated accumulated exposure to dust was calculated based on the following formula from the study by Rice et al.:

$$
\mathbf{E}(\mathbf{T})=\sum_{\mathbf{i}=1}^{\mathbf{n}} \mathbf{C}_{\mathbf{i}} \mathbf{T}_{\mathbf{i}}
$$

where $\mathrm{i}$ indexes the workers job, $\mathrm{Ci}$ is the airborne dust concentration at the $\mathrm{i}^{\text {th }}$ job and $\mathrm{Ti}$ is the employment time at the $\mathrm{i}^{\text {th }}$ job (21), and by assuming that $C$ was equal to $0.275 \mathrm{mgr} / \mathrm{m}^{3}$ per year based on the study by Azari et al. (13). In the study by Azari et al., occupational 
exposure of workers to crystalline silica in Iran has been measured in various industrial sectors such as stone cutting. The relationship between different exposure indexes and the signs and symptoms of respiratory disease were assessed using chi-square test. The means of different indexes were compared between the exposed and nonexposed groups, and also, between the stone carvers themselves using t-test. The correlation coefficients between spirometry parameters and the estimated accumulated annual mean of dust exposure was estimated by Pearson's correlation. Logistic regression was used to inverstigate the association between working conditions related to exposure and some pulmonary symptoms among the stone carvers. SPSS software (version 16, SPSS Inc., Chicago, IL, USA) and STATA software (version 12, StataCorp LP, College Station, $\mathrm{Tx}, \mathrm{USA}$ ) were used for analysis.

\section{Results}

In the city of Kerman and its suburbs, there was a sum of 35 stone carving or stone cutting workshops and mainly 1 to 2 workers worked in each workshop.

In total, 67 workers consented to participate in this study, completed the questionnaires, and went through medical exams. The mean age of these individuals was $37.0 \pm 8.3$ years, their work experience was $14.0 \pm 8.0$ years, and their mean annual estimated accumulative exposure to dust was $3.8 \pm 2.2 \mathrm{mgr} / \mathrm{m}^{3}$ per year based on the above mentioned formula. Occupational exposure of workers to crystalline silica in the stone cutting industry in Iran has been estimated to have a geometric mean of 0.275 (95 CI $0.191-0.397$ ) $\mathrm{mg} / \mathrm{m}^{3}$ (13). The mean surface of the workshops was $1,114 \pm 15 \mathrm{~m}^{2}$.

Table 1: The working characteristics of stone carvers in Kerman

\begin{tabular}{lc}
\hline \multicolumn{1}{c}{ Variable } & Number (\%) \\
\hline Devices used & $31(46.2)$ \\
Low dust & $18(26.9)$ \\
Medium dust & $18(26.9)$ \\
High dust & $12(17.9)$ \\
\hline Mask & $36(53.7)$ \\
Fabric or cloth & $19(28.3)$ \\
Usual mask & \\
Filtered masked & $61(91.0)$ \\
\hline Using working clothes & $6(8.9)$ \\
Yes & $0(0)$ \\
No & $67(100)$ \\
\hline Suitable ventilation & \\
Yes & $50(74.6)$ \\
No & $17(25.4)$ \\
\hline Working site & 67 \\
Mainly inside & \\
Mainly outside & Total
\end{tabular}

In the 67 workers of the comparison group, mean age was $37 \pm 7.1$, average work experience was $13.7 \pm 5.3$, and annual amount of dust exposure was trivial. The average surface of the workshops in which they worked was about $1,200 \mathrm{~m}^{2}$. The stone carvers and the comparison group were similar in regard to age, working experience, mean working hours per day, number of working days per week, gender, marital status, level of education, and smoking, addiction, and passive smoking status. The participant characteristics and P-values of comparisons have been presented in table 2 . 
Table 2: The characteristics of the participants (compared using chi-square ${ }^{2}$ and t-test)

\begin{tabular}{|c|c|c|c|}
\hline Categorical variables & $\begin{array}{c}\text { Stone carvers } \\
\text { No }(\%)\end{array}$ & $\begin{array}{c}\text { Comparison group } \\
\text { No }(\%)\end{array}$ & P-value \\
\hline $\begin{array}{l}\text { Gender } \\
\text { Male } \\
\text { Female }\end{array}$ & $\begin{array}{c}67(100) \\
0(0)\end{array}$ & $\begin{array}{c}67(100) \\
0(0)\end{array}$ & - \\
\hline $\begin{array}{l}\text { City of Birth } \\
\text { Kerman } \\
\text { Other }\end{array}$ & $\begin{array}{ll}25 & (37.3) \\
42 & (62.7) \\
\end{array}$ & $\begin{array}{ll}20 & (29.8) \\
47 & (70.2) \\
\end{array}$ & 0.361 \\
\hline $\begin{array}{l}\text { Marital Status } \\
\text { Single } \\
\text { Married } \\
\end{array}$ & $\begin{array}{cc}7 & (10.4) \\
60 & (89.6) \\
\end{array}$ & $\begin{array}{cc}8 & (12.0) \\
59 & (88.0) \\
\end{array}$ & 0.782 \\
\hline $\begin{array}{l}\text { Education } \\
\text { Below High school } \\
\text { High school or College }\end{array}$ & $\begin{array}{ll}37 & (55.2) \\
30 & (44.8) \\
\end{array}$ & $\begin{array}{ll}37 & (55.2) \\
30 & (44.8) \\
\end{array}$ & 1 \\
\hline $\begin{array}{l}\text { Smoker } \\
\text { Yes } \\
\text { No }\end{array}$ & $\begin{array}{ll}11 & (16.4) \\
56 & (83.5) \\
\end{array}$ & $\begin{array}{ll}10 & (14.9) \\
57 & (85.0) \\
\end{array}$ & 0.815 \\
\hline $\begin{array}{l}\text { Addiction } \\
\text { Yes } \\
\text { No } \\
\end{array}$ & $\begin{array}{cl}1 & (1.7) \\
66 & (98.3) \\
\end{array}$ & $\begin{array}{c}0(0) \\
67(100)\end{array}$ & 0.322 \\
\hline $\begin{array}{l}\text { Passive Smoking } \\
\text { Yes } \\
\text { No }\end{array}$ & $\begin{array}{ll}10 & (14.9) \\
57 & (85.1) \\
\end{array}$ & $\begin{array}{cc}7 & (10.4) \\
60 & (89.4) \\
\end{array}$ & 0.441 \\
\hline $\begin{array}{l}\text { Total } \\
\text { Continuous variables }\end{array}$ & $\begin{array}{c}67(100) \\
\text { Mean } \pm \text { SD }\end{array}$ & $\begin{array}{c}67(100) \\
\text { Mean } \pm \text { SD }\end{array}$ & P-value \\
\hline Age (years) & $37.0 \pm 8.3$ & $37.0 \pm 7.1$ & 0.998 \\
\hline $\begin{array}{l}\text { Years of working } \\
\text { Hours of work per day }\end{array}$ & $\frac{14.0 \pm 8.0}{7.5 \pm 2.3}$ & $\frac{13.7 \pm 5.3}{8.0 \pm 0}$ & $\begin{array}{l}0.793 \\
0.165\end{array}$ \\
\hline Number of work days per week & $5.8 \pm 0.8$ & $6.0 \pm 0$ & 0.194 \\
\hline
\end{tabular}

The results showed that complaints such as coughing, sputum, dyspnea, and sinusitis were significantly more common in the stone carvers (Table 3). The results also showed that the exposure group had more signs of obstructive $(6.7 \%)$ and obstructive-restrictive
(2.5\%) respiratory disorders than the comparison group $(\mathrm{P}<0.001)$. The estimated average annual cumulative dose of exposure to dust in workers was inversely correlated with spirometry parameters and this correlation was significant (Table 4).

Table 3: Comparison of pulmonary symptoms between stone carvers and comparison group (using Fisher's exact test)

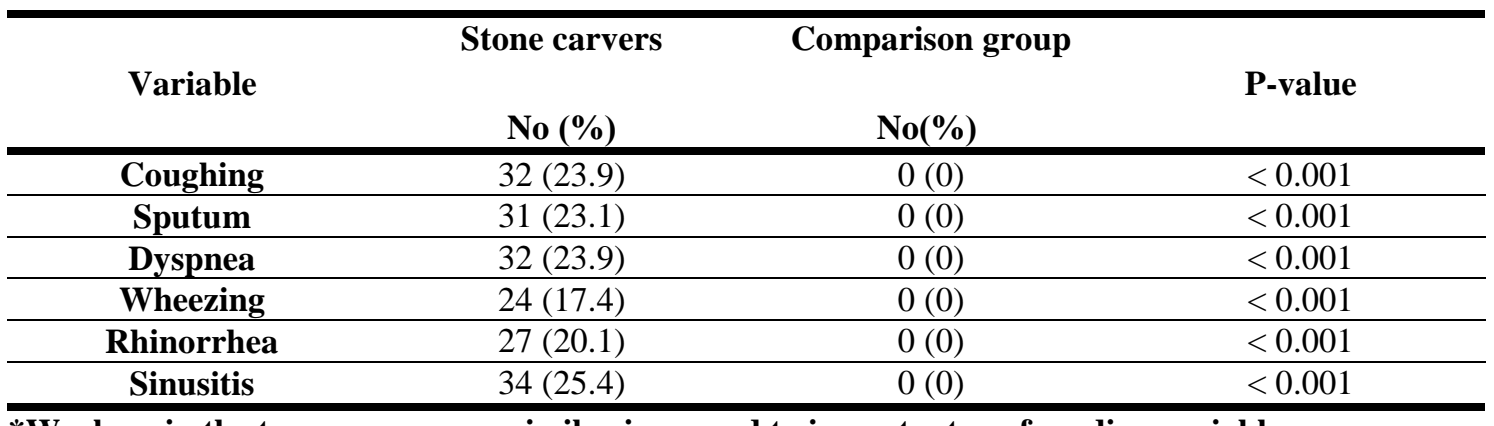

*Workers in the two groups were similar in regard to important confounding variables. 
Table 4: The Pearson's correlation coefficients between spirometry parameters and the estimated accumulated annual mean of dust exposure

\begin{tabular}{ccc}
\hline Outcome & Coefficient & P-value \\
\hline FVC & -0.79 & 0.151 \\
\hline FEV1 & -0.57 & 0.077 \\
\hline FEV1/FVC & -0.46 & 0.001 \\
\hline
\end{tabular}

*FVC: forced vital capacity, FEV1: forced expiratory volume in 1 second, FEV1/FVC: forced expiratory volume in 1 second/forced vital capacity

Table 5 shows the effect of working conditions related to exposure, and signs and symptoms of stone carvers. As can be seen, some of the factors related to exposure, such as working in confined enviroments, working in a smal workshop, not using appropriate masks, and working longer hours and more days per week, were significantly associated with exacerbation of pulmonary symptoms.

Table 5: The adjusted odds ratio for the association between working conditions related to exposure and some pulmonary symptoms among the stone carvers (odds ratios were adjusted for age, smoking, and years of work)

\begin{tabular}{|c|c|c|c|c|c|c|}
\hline & Coughing & Sputum & Dyspnea & Rhinorrhea & Wheezing & Sinusitis \\
\hline $\begin{array}{l}\text { Working site } \\
\text { Outside } \\
\text { Inside }\end{array}$ & $\begin{array}{l}1 \\
2.4(2.22-3.1)\end{array}$ & $\begin{array}{l}1 \\
1.8(1.6-2.5)\end{array}$ & $\begin{array}{l}1 \\
2.6(2.2-3.9)\end{array}$ & $\begin{array}{l}1 \\
2.3(1.8-5.6)\end{array}$ & $\begin{array}{l}1 \\
2.5(13-6)\end{array}$ & $\begin{array}{l}1 \\
1.9(1.3-3.2)\end{array}$ \\
\hline $\begin{array}{l}\text { Device used } \\
\text { Low dust } \\
\text { Medium dust } \\
\text { High dust } \\
\end{array}$ & $\begin{array}{l}1 \\
0.2(0.05-2.0) \\
2.0(1.5-4.0)\end{array}$ & $\begin{array}{l}1 \\
1.5(0.19-3.1) \\
1.25(1.11-3.0)\end{array}$ & $\begin{array}{l}1 \\
0.87(0.2-1.8) \\
2.2(1.7-4.1) \\
\end{array}$ & $\begin{array}{l}1 \\
2.2(0.4-1.12) \\
2.4(1.6-5.5)\end{array}$ & $\begin{array}{l}1 \\
1.28(0.03-3.3) \\
2.5(1.3-7.0)\end{array}$ & $\begin{array}{l}1 \\
1.5(2.1-3.3) \\
1.9(1.2-4.0)\end{array}$ \\
\hline $\begin{array}{l}\text { Mask } \\
\text { Fabric, cloth } \\
\text { Usual mask } \\
\text { Filtered mask } \\
\end{array}$ & $\begin{array}{l}1 \\
0.31(0.01-2.06) \\
0.08(0.01-0.61)\end{array}$ & $\begin{array}{l}1 \\
0.59(0.09-3.9) \\
0.65(0.04-0.8)\end{array}$ & $\begin{array}{l}1 \\
0.11(0.01-1.1) \\
0.04(0.09-0.42)\end{array}$ & $\begin{array}{l}1 \\
0.34(0.05-2.37) \\
0.42(0.02-0.96)\end{array}$ & $\begin{array}{l}1 \\
0.59(0.09-3.9) \\
0.17(0.02-0.45)\end{array}$ & $\begin{array}{l}1 \\
0.9(0.14-5.9) \\
0.22(0.03-0.5)\end{array}$ \\
\hline $\begin{array}{lr}\begin{array}{l}\text { Using } \\
\text { when }\end{array} & \begin{array}{r}\text { water } \\
\text { stone }\end{array} \\
\text { carving } & \\
\text { Yes } & \\
\text { No } & \\
\end{array}$ & $\begin{array}{l}1 \\
1.61(1.1-.5 .3)\end{array}$ & $\begin{array}{l}1 \\
1.12(1.02-2.29)\end{array}$ & $\begin{array}{l}1 \\
1.33(1.2-3.1)\end{array}$ & $\begin{array}{l}1 \\
1.59(1.3-2.05)\end{array}$ & $\begin{array}{l}1 \\
1.91(1.6-3.1)\end{array}$ & $\begin{array}{l}1 \\
1.41(1.2-3.7)\end{array}$ \\
\hline $\begin{array}{l}\text { Using working } \\
\text { clothes } \\
\text { Yes } \\
\text { No }\end{array}$ & $\begin{array}{l}1 \\
1.93(1.13-5.3)\end{array}$ & $\begin{array}{l}1 \\
1.8(1.43-3)\end{array}$ & $\begin{array}{l}1 \\
1.56(1.33-2.3)\end{array}$ & $\begin{array}{l}1 \\
1.25(1.04-3.9)\end{array}$ & $\begin{array}{l}1 \\
1.7(1.32-3.11)\end{array}$ & $\begin{array}{l}1 \\
1.9(1.44-4)\end{array}$ \\
\hline $\begin{array}{l}\text { Hours per day } \\
\text { stone carving } \\
<2 \text { hours } \\
2-10 \text { hours }\end{array}$ & $\begin{array}{l}1 \\
1.77(1.25-3.1)\end{array}$ & $\begin{array}{l}1 \\
1.65(1.1-3.3)\end{array}$ & $\begin{array}{l}1 \\
2.22(1.3-5.1)\end{array}$ & $\begin{array}{l}1 \\
1.55(1.2-3.2)\end{array}$ & $\begin{array}{l}1 \\
2.0(1.69-3.5)\end{array}$ & $\begin{array}{l}1 \\
1.66(1.5-2.1)\end{array}$ \\
\hline $\begin{array}{l}\text { Days per week } \\
\text { stone carving } \\
\text { less than } 3 \text { days } \\
\text { 3-7 days }\end{array}$ & $\begin{array}{l}1 \\
2.2(1.4-3.1)\end{array}$ & $\begin{array}{l}1 \\
1.33(1.06-2.7)\end{array}$ & $\begin{array}{l}1 \\
1.58(1.3-4.1)\end{array}$ & $\begin{array}{l}1 \\
1.4(1.02-3.5)\end{array}$ & $\begin{array}{l}1 \\
1.65(1.6-2.3)\end{array}$ & $\begin{array}{l}1 \\
1.9(1.7-3.3)\end{array}$ \\
\hline $\begin{array}{l}\text { Advised to use } \\
\text { protective gear } \\
\text { Yes } \\
\text { No }\end{array}$ & $\begin{array}{l}1 \\
1.28(1.1-3.3)\end{array}$ & $\begin{array}{l}1 \\
1.22(1.03-2.4)\end{array}$ & $\begin{array}{l}1 \\
1.3(1.01-3.9)\end{array}$ & $\begin{array}{l}1 \\
1.35(1.4-4.1)\end{array}$ & $\begin{array}{l}1 \\
1.6(1.2-3.2)\end{array}$ & $\begin{array}{l}1 \\
1.4(1.04-3.6)\end{array}$ \\
\hline $\begin{array}{l}\text { Shown how to } \\
\text { use protective } \\
\text { gear in practice } \\
\text { Yes }\end{array}$ & & & & & & \\
\hline
\end{tabular}




\begin{tabular}{|c|c|c|c|c|c|c|}
\hline No & $\begin{array}{l}1 \\
1.55(1.1-2.5)\end{array}$ & $\begin{array}{l}1 \\
1.35(1.5-3.7)\end{array}$ & $\begin{array}{l}1 \\
1.78(1.3-3.09)\end{array}$ & $\begin{array}{l}1 \\
1.55(1.21-3.2)\end{array}$ & $\begin{array}{l}1 \\
1.89(1.14-4)\end{array}$ & $\begin{array}{l}1 \\
2.12(1.6-5)\end{array}$ \\
\hline $\begin{array}{l}\text { Workshop } \\
\text { surface } \\
\text { Large }(100-2000 \\
\left.\mathrm{m}^{2}\right) \\
\begin{array}{l}\text { Small } \\
\left.\mathrm{m}^{2}\right)\end{array}\end{array}$ & $\begin{array}{l}1 \\
1.6(1.2-3.3)\end{array}$ & $\begin{array}{l}1 \\
2.5(1.5-3.5)\end{array}$ & $\begin{array}{l}1 \\
1.7(1.5-3.1)\end{array}$ & $\begin{array}{l}1 \\
1.46(1.05-3)\end{array}$ & $\begin{array}{l}1 \\
1.6(1.2-4)\end{array}$ & $\begin{array}{l}1 \\
1.55(1.2-4.1)\end{array}$ \\
\hline $\begin{array}{l}\text { Area of doors } \\
\text { and windows } \\
\operatorname{Big}\left(10-50 \mathrm{~m}^{2}\right)\end{array}$ & 1 & 1 & 1 & 1 & 1 & 1 \\
\hline
\end{tabular}

\section{*Logistic regression}

The radiographic findings in these stone carvers have been presented in table 6 . However, we did not find any significant association between the radiographic findings and exacerbation of clinical symptoms or the estimated mean accumulative exposure.

Table 6: Radiographic findings in the stone carvers

\begin{tabular}{lc}
\hline Radiographic finding & Number (\%) \\
\hline Costophrenic angle blunting & $2(3.0)$ \\
\hline Calcification & $8(11.9)$ \\
\hline Lymphadenopathy & $2(3.0)$ \\
\hline Profusion* & $2(3.0)$ \\
\hline Small round opacity & $27(40.3)$ \\
Less than $1.5 \mathrm{~mm}$ & $16(23.9)$ \\
Between 1.5 and $3 \mathrm{~mm}$ & $3(4.4)$ \\
More than 3 mm & \\
\hline Small irregular opacity & $29(43.3)$ \\
Between 2 to 3 mm & $17(25.4)$ \\
More than 3 mm &
\end{tabular}

*A score reflecting the number or frequency of visible lesions on chest radiographs of individuals with pneumoconiosis.

\section{Discussion}

Our study shows that the stone carvers of Kerman work in inappropriate conditions, their working enviroment does not have suitable ventilation, and some workers use a piece of cloth or inappropriate masks during work. This situation exposes them to high amounts of dust. Based on the study by Azari et al. in Tehran, Iran, in which the mean annual exposure of stone carvers has been estimated
(12), we estimated that the mean exposure to dust in the stone carvers of Kerman was about $3.8 \mathrm{mg} / \mathrm{m}^{3}$ annually. This amount is higher than the Iranian Occupational Health Standard and the American Conference of Industrial Hygienists (ACGIH) and Occupational Safety and Health Administration (OSHA) (0.05 $\mathrm{mg} / \mathrm{m}^{3}$ ) standards. The study by Rice et al. and this study have used the previously mentioned formula to estimate the annual accumulative mean of exposure to dust in dusty industries 
and in different working units such as stone cutting, stone carving, labratory, stone extraction, sand blast, and transportation units (21).

Different studies performed on stone carvers and industries related to stone and silica (such as tiling, granite carving, mining, and cement factories) have shown high levels of accumulated annual dust exposure. For example, in the study by Neghab et al. on the workers of a cement factory, the density of respirable dust was $26 \mathrm{mg} / \mathrm{m}^{3}$ (22).

Furthermore, a study on the stone carvers in Brazil in 1994 showed that the mean density of respirable dust in their work place was 1.5 $\mathrm{mg} / \mathrm{m}^{3}$ (23). Another study in 2001 on the stone carvers in Thailand showed that the mean exposure density to dust was in some cases even up to 8.8 times that of the standard exposure (11). The reason for this difference in exposure in different industries can be the use of old or new machinery, the maintence of the devices used, usage of control systems, cleanliness of the enviroment, and etc. (24-27). In the present study, the two groups (stone carvers and the sign making workers) were similar in regard to socioeconomic and demographic factors and none of the participants had a history of respiratory diseases, trauma, or thoracic surgery before employment. There was no significant difference between the two groups in terms of confounding factors such as age, average years of employment, average daily working hours, smoking, drug abuse, history of respiratory diseases, and socioeconomic factors. Therefore, it seems that the decrease in pulmonary function, respiratory symptoms, and changes in radiographic images were related to exposure to dust and coarse particles.

Studies have shown that exposure to dust particles in the working enviroments can lead to respiratory diseases and even lung and laryngeal cancer in workers. Simultaneous smoking and/or drug abuse can also have an exacerbating effect on the disease of these workers $(26,28,29)$. However, in our study, the pack-year for cigarette use was similar in the exposed and the comparison group, which means that we were not able to detect the synergistic effect of smoking on exacerbating respiratory symptoms.

This study was performed based on the results of exposure and outcome of the questionnaire including respiratory symptoms, spirometry and radiography results, and respiratory physical examination results. Other studies have reported similar findings. For example, a study by Neghab et al. in 2005 on cement factory workers showed that respiratory signs such as coughing, sputum, wheezing, and dyspnea were more prevalent in the exposed than the comparison group. Moreover, abnormal radiological findings and pulmonary infiltration were more prevalent in the exposed group and spirometry showed significant changes in pulmonary indexes in the exposed group (22).

A study by Yingratansuk in 2001 on 97 stone carving workers in Tailand showed that the prevalence of silicosis and tuberculosis was, respectively, $2 \%$ and $4 \%$ (11). Other studies, such as those by Forastiere and Cavariani, on tile workers in Italy showed that the $\mathrm{FVC}_{\mathrm{FEV}}$ (forced vital capacity/forced expiratory volume in 1 second) parameters were significantly decreased in spirometry $(25$, 30).

A study by Gotkar showed a $32.5 \%$ prevalence of respiratory disease among workers in the stone carving and stone cutting industry, and also, a significant decrease in pulmonary function parameters especially in workers with more than 20 years of exposure (24). Different sources show that pulmonary disfunction increases with age, exposure time, smoking, and the coexistance of pulmonary airway diseases $(23,25,31)$. A study by Aghili-nejad et al. in 2001 on stone carvers showed that about $12 \%$ of the workers had coughing, $0.5 \%$ had coughing and dyspnea, and $0.4 \%$ of the workers had abnormal spirometry results. Workers with silicosis $(10 \%)$ had on average 44 years and at least 5 years work experience (30). Similar to our study, this study showed a 
high prevalence of respiratory symptoms among the exposed workers. Nevertheless, the discrepencies between respiratory symptoms in this study compared with our study are probably related to the higher age range of these workers and the smoking status which has a confounding effect.

A study by Zeleke in 2010 on 127 cement workers in two different sections of the factory in comparison to the control showed that the prevalence of repiratory symptoms was significantly higher in the exposed group and the pulmonary function parameters (FEV1, FVC, and FEV1/FVC) were significantly lower in the exposed groups (24).

Despite the work experience and accumulated annual exposure of the workers to dust, and the presence of respiratory symptoms (such as dyspnea, sputum, wheezing, rhinitis, and synositis), the results of this study did not show an increase in silicosis or other respiratory diseases such as asthma, emphysema, or bronchitis in the exposed group. One of the reasons for this can be the healthy worker effect. This type of bias is due to the fact that the workers chosen for working in these workshops were healthy individuals, and the fact that some of these workers are uninsured and after their health deteriorates they are dimissed from work.

Among the other important results of this study that have not been mentioned in other studies was the effect of working conditions on the stone carvers' symptoms. This study showed that in smaller workshops, when using special equipment, not using appropriate masks, not using working clothes, and poor ventilation, the prevalence of respiratory symptoms increases significantly. However, we did not find any other study to compare our results with.

We were not able to classify low, medium, and high dust producing devices based on actual dust measurments. This may explain why despite the worsening of symptoms in the workers using the high dust producing devices, those using medium dust producing devices did not show exacerbation in most symptoms.
We did not find a significant relation between radiographic findings and clinical symptoms or the estimated annual accumulated dose of exposure. Confirming our findings, occupational disease textbooks have mentioned that the chest radiograph is relatively insensitive for the diagnosis of pneumoconiosis. Furthermore, radiographic signs in the absence of additional clinical data can be misleading in individual patients and there is no clear correlation between radiologic signs and clinical presentation of patients (32). The reason for different results in the studies on stone carvers from different nations is probably due to different univariate or multivariate analyses, different confounders included in the analysis (such as smoking, age, and job experienc), and the types of stone, type of dust, the concentation of dust, the size of particles, and etc.

Respiratory symptoms associated with fine particles have been reported in the past. However, there is limited literature about this exposure and its complications in different occupational groups such as stone carvers. This study also shows that despite our knowledge about the consequences of particle exposure, we have still not been successful in controlling exposure in specific workplaces and occupational groups.

According to the law, employers in Iran are obliged to take care of their workers' safety and send their employees for work related medical examination at least once a year and keep a record of their examination.

Nevertheless, we assume that two factors preclude appropriate medical examination in this population. First, is the fact that the stone carving industry usually uses seasonal workers, which work for a few months, and then, leave for a better job or the employer asks them to leave permanently or temporarily after realizing that they have developed respiratory problems. Second, this industry uses illegal foreign (mainly Afghan) workers which are kept hidden from inspectors.

Another limitation of the study was that although all stone carvers were invited to 
participate, there was a small hidden population which the employers would not allow access to; an important part of this inaccessible population consisted of illegal migrants. However, our team members made efforts to completely explain the research for the employers and convince them that their aim was only research, and no information would be handed to the Labor Organization or other legal bodies.

\section{Conclusion}

Although exposure to dust and silica is a well known factor in the etiology of respiratory disease, the present study and other studies show that the situation of workers in dusty work environments is not satisfactory and the prevalence of repiratory symptoms is still high. These results emphasize the importance of controlling exposure to dust in these workplaces.

\section{Acknowledgement}

The authors would like to thank Dr. Deborah Glass (from Australia) and Dr. Carol Rice (from the US) for their comments and guidance in conducting this study.

This study was approved by the Enviromental Medicine Research Committee at the School of Public Health and was funded by Grant No. 89/242 from Kerman University of Medical Sciences, Kerman, Iran.

The authors also wish to thank all of the hardworking stone carvers who participated in this study.

\section{Conflict of interest: Non declared}

\section{References:}

1. Guthrie GD Jr, Heaney PJ. Mineralogical characteristics of silica polymorphs in relation to their biological activities. Scand J Work Environ Health 1995; 21 Suppl 2:5-8.
2. NIOSH. A guide to working safety with silica. U.S. Department of labor National institute for Occupational Safety and Health; 1998: 1-2.

3. Stealman J. Encyclopaedia of Occupational Health and Safety. $4^{\text {th }}$ Edition. Geneva, Switzerland: International Labour Office 1998; 1-10.

4. Calvert GM, Rice FL, Boiano JM, Sheehy JW, Sanderson WT. Occupational silica exposure and risk of various diseases: an analysis using death certificates from 27 states of the United States. Occup Environ Med 2003; 60(2):122-9.

5. Matheson MC, Benke G, Raven J, Sim MR, Kromhout H, Vermeulen R, et al. Biological dust exposure in the workplace is a risk factor for chronic obstructive pulmonary disease. Thorax 2005; 60(8):645-51.

6. Bergdahl IA, Toren K, Eriksson K, Hedlund U, Nilsson T, Flodin R, et al. Increased mortality in COPD among construction workers exposed to inorganic dust. Eur Respir J 2004; 23(3):402-6.

7. Oxman AD, Muir DC, Shannon HS, Stock SR, Hnizdo E, Lange HJ. Occupational dust exposure and chronic obstructive pulmonary disease. A systematic overview of the evidence. Am Rev Respir Dis 1993; 148(1):38-48

8. Hughes JM, Weill H, Checkoway H, Jones RN, Henry MM, Heyer NJ, et al. Radiographic evidence of silicosis risk in the diatomaceous earth industry. Am J Respir Crit Care Med 1998; 158(3):807-14.

9. Carson R. Kelley TR. A Brief Review of Silicosis in the United States. Environ Health Insights 2010; 4:21-6.

10. Aghilinejad M, Jamaati $\mathrm{H}$, Farshad A, Mostafaie M, Atari G. Investigation of prevalence rate of silicosis in silica powder production workers in Azandaria - Mayler in 2001-2002. Iran Occupational Health Journal 2006; 3(1):76-80.

11. Yingratanasuk $T$, Seixas $\mathrm{N}$, Barnhart $\mathrm{S}$, Brodkin D. Respiratory health and silica exposure of stone carvers in Thailand. Int $\mathbf{J}$ Occup Environ Health 2002; 8(4):301-8.

12. Azari MR, Rokni M, Salehpour S, Mehrabi Y, Jafari MJ, Moaddeli AN, et al. Risk Assessment of Workers Exposed to Crystalline Silica Aerosols in the East Zone of Tehran. Tanaffos 2009; 8(3):43-50.

13. Akbar-Khanzadeh F, Brillhart RL. Respirable crystalline silica dust exposure during concrete finishing (grinding) using hand-held grinders in the construction industry. Ann Occup Hyg 2002; 46(3):341-6.

14. Mathur ML. Pattern and predictors of mortality in sandstone quarry workers. Indian J Occup Environ Med 2005; 9(2):80-5.

15. NIOSH. Health Effects of Occupational Exposure to Respirable Crystalline Silica Department of health and human services Centers for Disease Control and Prevention National Institute for Occupational Safety and Health; 2002. 
16. World Health Organization (WHO). Fact Sheet on silicosis. Silicosis. Geneva: No. 238, May 2008. Avaiable from: http://www.who.int/mediacentre/factsheets/fs2 38/en/ [last cited on 2009 Apr 20].

17. Antao VC, Pinheiro GA, Terra-Filho M, Kavakama J, Müller NL. High-resolution CT in silicosis: correlation with radiographic findings and functional impairment. J Comput Assist Tomogr 2005; 29(3):350-6.

18. Pérez-Alonso A, Córdoba-Doña JA, MillaresLorenzo JL, Figueroa-Murillo E, GarcíaVadillo C, Romero-Morillo J. Outbreak of silicosis in Spanish quartz conglomerate workers. Int J Occup Environl Health 2014; 20(1):26-32

19. Attfield MD, Morring K. An investigation into the relationship between coal workers' pneumoconiosis and dust exposure in U.S. coal miners. Am Ind Hyg Assoc J 1992; 53(8):48692.

20. NIOSH. Hazard Review: Health effects of occupational exposure to respirable crystalline silica 2002. Department of Health and Human Services. Centers for Disease Control and Prevention National Institute for Occupational Safety and Health, USA. Available from: URL: http://www.cdc.gov/niosh

21. Rice C, Harris RL, Lumsden JC, Symons MJ. Reconstruction of silica exposure in the North Carolina dusty trades. Am Ind Hyg Assoc J 1984; 45(10):689-6.

22. Neghab M, Choobineh A. Work-related respiratory symptoms and ventilatory disorders among employees of a cement industry in Shiraz, Iran. J Occup Health 2007; 49(4):2738.

23. Ghotkar VB, Maldhure BR, Zodpey SP. Involvement of lung and lung function tests in stone quarry workers. Indian Journal of
Tuberculosis 1995; 42:155-60.

24. Zeleke ZK, Moen BE, Bratveit M. Lung function reduction and chronic respiratory symptoms among workers in the cement industry: A Follow up study. BMC Pulm Med 2011; 11(1):50.

25. Cavariani F, Di Pietro A, Miceli M, Forastiere $\mathrm{F}$, Biggeri A, Scavalli $\mathrm{P}$, et al. Incidence of silicosis among ceramic workers in central Italy. Scand J Work Environ Health 1995; 21(2):58-62.

26. Anto VCS, Pinheiro GA, Kavakama J, TerraFilho M. High prevalence of silicosis among stone carvers in Brazil. Am J Ind Med 2004; 45(2):194-201.

27. Steenland K, Goldsmith DF. Silica exposure and autoimmune diseases. Am J Ind Med 1995; 28(5):603-8

28. Ulm K, Gerein P, Eigenthaler J, Schmidt S, Ehnes H. Silica, silicosis and lung-cancer: results from a cohort study in the stone and quarry industry. Int Arch Occup Environ Health 2004; 77(5):313-8.

29. Ulm K, Waschulzik B, Ehnes H, Guldner K, Thomasson B, Schwebig A, et al. Silica dust and lung cancer in the German stone, quarrying, and ceramics industries: results of a case-control study. Thorax 1999; 54(4):347-51.

30. Aghilinejad M, Jamaati MR, Farshad AA. Prevalence of Silicosis among Workers in Stone-Cutter and Silica Powder Production Factories. Tanaffos 2006; 5(3):31-6.

31. Neghab M, Hasanzadeh J. Evaluation of respiratory disorders associated with occupational inhalation exposure to raw materials used in ceramic production. Iranian Journal of Epidemiology 2009; 4(3-4):27-33.

32. Rom WN, Markowitz SB. Environmental and Occupational Medicine. $4^{\text {th }}$ Edition. Lippincott: Williams \& Wilkins; 2007. 